\title{
Postwar Library Buildings
}

$\mathrm{T}$

He Cooperative Committee on Library Building Plans is not a formal committee but rather a small congress of somewhat fluctuating membership which meets from time to time to discuss common problems encountered in preparing plans for forthcoming college or university library buildings. This committee was self-established and owes responsibility to no one save itself. It was created as sequel to a letter from President Dobbs, of Princeton University, inviting a number of university presidents to send representatives to a meeting for the purpose of discussing mutual problems in the planning of postwar library buildings. The first meeting was held at Princeton in December 1944, the second at the University of Missouri in the spring of 1945 , and the third at Orange, Va., in the fall of that year. A further meeting is projected for the State University of Iowa this spring, at which time it is hoped to study a mock-up of the very interesting, fully flexible building proposed for that institution.

At the first meeting nine of the eleven originally invited institutions were represented, as follows: Princeton University, Rutgers University, University of Pennsylvania, State University of Iowa, Washington State University, University of Maine, University of Missouri, University of North Carolina, and the Massachusetts Institute of Technology. None of the representatives has dropped his interest or failed to attend subsequent meetings, and Messrs. Boyd of

1 Based on a paper presented at the Conference of Eastern College Librarians, Nov. 24, 1945.
Princeton, chairman, David of Pennsylvania, secretary, Ellsworth of Iowa, Powell of Missouri, and Rush of North Carolina have been steadfast and ardent attendants.

By the time of the second meeting, the word had spread and a number of additional institutions sent representatives. Since that time there has been some fluctuation among the newcomers, but Metcalf of Harvard and Heaps of Rice Institute have made regular contributions while at various times the committee has also enjoyed the participation of the University of Wisconsin, Claremont Colleges, and others.

The original purpose of the committee was to make a formal study of the general problem of the college library building, probably with the aid of a grant from a foundation, and to make a formal report of findings. Circumstances have altered this program and the objectives have become more personal to the membership.

A characteristic meeting has extended over several days and the attendance has been broadened to include university administrators (the president of the State University of Iowa, for example, attended the Orange meeting), the architects of buildings which are being planned, and experts in various techniques of supreme importance to a library building, such as prominent heating and ventilating engineers, illumination engineers, and manufacturers of stack and other library equipment. At every such meeting the small size of the gathering has permitted free and wide-ranging informal discussion stretching from the broadest questions of library management as they 
might affect a building plan, to a detailed and frank criticism of the plans of specific buildings as they were presented to the committee by their individual sponsors.

From these meetings each individual representative has surely obtained a great deal which should help him with his individual problem. The question of whether the committee might not properly prepare a report for wider circulation which would make at least the generalizations available to more planners is still under consideration. Meanwhile, the committee authorized the writer to present informally some of the findings in a paper before the November 1945 meeting of the Conference of Eastern College Librarians. The statement which follows is a paraphrase of this paper modified for a reading audience and, as in the case of the paper, must be regarded as the personal conclusions of a member of the committee, a relative newcomer to "library business, and in no sense a formal report of the committee.

\section{Influencing Factors}

Two sets of factors have clearly influenced the thinking of all the participants; one is a set of fears, the other a set of basic queries as to the activities which ought to be carried on in these new buildings.

Persons about to build library buildings in universities or colleges appear to be haunted by three specters - the specter of the architect, the specter of growth, and the specter of change. These are, of course, the very same specters which frighten a sensible person about to build any sort of new building, but they seem to be more dramatically arrayed than usual in the subject case.

To the architect is ascribed, and with considerable justification, the crushing load imposed on most librarians who now occupy the beautiful buildings of many a campus.
It has been one of the misfortunes of the library that it has had to occupy a central position on the campus, and that it has naturally epitomized the dignity and scholarly quality of the institution in greater degree than most educational buildings are called upon to do. The natural result has been that it has especially engaged the attention of those who seek "amenity" for the campus in external expressions; it has become one of the show places of the institution and often the show place. Small imaginations have taken refuge in monumental staircases, a forced symmetry for nonsymmetrical activities, colonnades and porticos which may or may not look well according to one's taste but which always steal light. Especially, the creators have built finished things which, on the one hand, could not be readily altered to accommodate new or changed activity and, on the other, could brook no addition for growth without having their form spoiled; when additions have become mandatory this has resulted in the addition of other balanced and still less functional elements.

\section{Responsibility Shared}

Certainly the architect as the deus ex machina of this process must bear a heavy share of the blame, but he should not stand in the dock alone. Donors, trustees, perhaps even college presidents, and, surely, alumni must bear their share of the responsibility. Even the librarian himself can scarcely escape censure: even where he was not an active participant in the planning, as has too often been the case, he has been a sensible and important influence on the campus; he has surely known that his library was to be built; he has probably not been sufficiently combative. The librarian who is not sufficiently consulted has, presumably, not been vocal enough.

It is doubtful that this can be considered 
entirely a dead issue. The librarians of the committee are, generally speaking, influential at their respective institutions. They seem to be able to have plenty to say about their new buildings. But even some of the plans which have been presented to this group seem to be laboring under the dead hand of an old-fashioned approach to the architectural problem.

It is certainly too much to expect that all the institutions about to build libraries might be willing to say to their architects: "Build us what we need for a library and forget Williamsburg, Bourges, Oxford, and Rome." But there surely could be more who would speak thus and mean it. It is hard, indeed, to understand the philosophy of university trustees and donors and administrators who are so bold in their approaches to pedagogy and to scientific research and so timid in their approach to architecture. It is hard to see how this body of educated men can find standards of building taste only in forms which have received the cachet of nobility through time, how they can assert a philosophy which always insists that every new building must not only be compatible with but essentially identical with what is already on campus. The very Europe which these people admire and which they still copy long after Europe itself has ceased such copying save in dogmatic states-this Europe was the living demonstration of the ability of well-designed buildings of every period to live together without clash.

\section{Architect of Today}

Many architects, it is true, are by education and habit unfitted to do anything more; but there are also many who can build a building of today for today, and these men will be found not only among the ranks of the radical or so-called modern architects. Today it is unnecessary to accept the crip- pling hand of the architect who will not first think of how the building works, however much this limitation may have been inevitable in the past.

Indeed, in the very change in the architectural air there lies a greater challenge than in the fear of what has happened before. This challenge can be met easily if the librarian is on his toes; if he is so alert that it will not only be a challenge but a help.

The architect of today is a coordinator. $\mathrm{He}$ is necessarily adroit at surveying opinion, at synthesizing conclusions, at writing a program based on these conclusions, and at expressing them in building form. Once these conclusions have been expressed in presentation drawings, once someone of influence has looked upon these drawings and found them good, it will be very hard to change them. The risk, then, is that the architect will not only design the building but will design the program for the activities subsequently to be pursued. If the librarian has not crystallized his own program before this process has taken place he will find himself trying to administer the program of another person-a person with no further responsibility, a program with which the librarian may be completely out of sympathy.

It is hard to escape the conclusion that this failure of librarians to crystallize their own thinking is as much responsible for the failures of the past as has been the undirected thirst for "beauty." It is possible in the meetings of the committee to detect some uncertainties in librarians' minds on very big issues. If these remain unclarified in the mind of the librarian at the time he comes to face the architect, the librarian is likely to lose. The architect will know more about the problem than the librarian, or at least he will appear to know more in any conference. 


\section{Prepare a Program}

At least one way in which the librarian can prepare himself for what will be, at worst, a conflict in which he should prevail and, at best, a pleasant and successful collaboration, is to crystallize his thinking by preparing a written program in black and white. This was the technique which was employed at the writer's institution.

The advantage of the written program, prepared before any sketches have been made, is that it can set out all the desiderata without regard to whether or not all can be achieved; it can establish the priorities of the desiderata so that if anything needs to be sacrificed it is clear what it shall be; and it affords a checklist which will make it abundantly clear exactly what has been sacrificed.

The technique at M.I.T. was about as follows: The library staff first prepared an extensive and detailed statement dealing primarily with library processes, and the director of libraries then wrote a first draft of a program which included all policy considerations. This program was written in very positive form. Even where questions had not been answered in the mind of the writer he made a categorical affirmation on every point. This was because experience had shown that clean-cut and definitive debate occurs only when one favors or opposes a specific proposal and seldom when one is asked to debate alternatives. This specific doctrine was then discussed and modified in a full meeting of the library staff; the modified draft was similarly treated in a full meeting of the faculty committee on the library which, at M.I.T., includes a representative for each department; the second modification was again adjusted at a meeting of the corporation visiting committee on the library; and the final draft was adopted by the administrative council of M.I.T.
This doctrine was not expected to go unchallenged from the architect, who was encouraged to make his own independent study, but in all subsequent discussion it has afforded a foundation which has always made it clear to the library administration what it was doing when it agreed to a change. There have not been many changes.

\section{Best Procedure?}

There can be difference of opinion as to whether this has been the very best procedure. The architects of M.I.T. are inclined to think that a better original program might have been produced had the collaboration of the library administration and the architect begun before the writing of the program, and been carried through this writing. The writer demurs because he needed the clarity of purpose which the writing has brought and because the very nature of the program had an important role to play in the selection of an architect who, by temperament and skill, was demonstrably able to work in accordance with the spirit of the program.

On the whole, it appears that most librarians would profit if they would undertake such a task before the architect has been selected.

From this experience and from the meetings of the committee it is possible to make some categorical statements:

I. It is essential that the librarian be a fullfledged member of the building committee for the library and be kept fully apprised of all the thinking and planning of the architect-even the most preliminary.

2. It is essential that, before meeting with the architect, the librarian shall have formed for himself a clear idea of what he is trying to accomplish in his new building.

3. Bewildered as librarians may be, it is essential that they do not tolerate the accusation from the architect or anyone else that they do not know what they are doing. All 
professions indulge in self-criticism, even architects, and this must not be construed as a sign of weakness but rather as a sign of strength.

4. In all matters which deal with policy of library management, the desires of the librarian must be carried out in the building even when these are in conflict with the opinion of the architect as to how the library ought to function. These opinions should be carefully considered because nonprofessional and outside views are often the right views. But after this consideration it must be remembered that the librarian will have to administer the building while the architect will be elsewhere. It is better to try to make your own mistakes work than to be pestered by those of someone else.

5. On the other hand, the architect will inevitably be more expert on matters of floor finish, ventilation, illumination, and circulation. After helping to set standards of performance, the librarian should trust the architect in such matters.

6. The collaboration between architect and librarian can be one of the most pleasurable experiences in the life of either and should not be spoiled by fear, disrespect, or distrust.

If such principles are followed it is possible to look with some confidence to the kind of library buildings which will be produced. Eternal vigilance will be required, and the librarian cannot stop when he has given his written program to the architect but must stay with the job until the keys are placed in his hand.

\section{Specter of Growth}

The specter of growth is epitomized by Fremont Rider's charts. This is not the place to debate the validity of extrapolating into the future a curve, the abscissa of which is time; nor will it help to discuss the various proposals which have been made to solve the problem of storage. Indeed, it is doubtful whether storage is nearly so critical a problem as means of reference to large amounts of material, even if these can all be put on tiny cards. It seems abundantly clear that libraries which are not now full-scale research libraries in all fields must limit their aspirations to quality in a few fields rather than to quantity in many; and that even the few great university research libraries of the world will have ultimately to come to similar conclusions, though on a broader scale, if only through the limitation which ultimately overtakes any university budget. The solution, as everyone well knows, lies in a full-scale cooperation about which everyone agrees in principle. The trouble here, as yet, lies in the natural ambitions of all of us. In a recent discussion of a departmental versus a central library system at M.I.T., it was suggested that each department wanted a departmental library for itself but a central system for everyone else. The parallel is obvious. This cooperation in accession policy will inevitably come about, and at that time the problem of growth will seem much less formidable.

\section{A Regional Cooperative Plan}

For the average university or college library, at any rate, the problem of growth can be met more readily and for a longer future by a regional cooperative plan than by anything which can be done in the planning of the building. None of the solutions for compact storage, interesting as each may be, has reached a point of development where the librarians now planning buildings could be prepared to abandon the stack or even limit it materially, on the ground that storage would be more compact. On the other hand, many libraries now seem ready to set an upper limit to the material which can ever be effectively used on the campus and to be prepared to take care of the rest of the needs through cooperative accession and interlibrary loan, plus the off-campus storage warehouse for little-used possessions. Capacity of stacks which are being 
calculated on this premise runs roughly to three times the present holdings of the library in most cases. Libraries in rapidly growing institutions and in communities which are remote from great library centers and where there is not already a rich library resource, may have to use a different factor, but the principle can remain the same. The solution can admittedly be accepted with greater equanimity by institutions with stabilized enrolment and no aspirations for gigantic growth, than by younger or less settled institutions whose desires both for student population and diversity of curriculum are as yet unattained.

Having established a firm capacity for the on-campus stacks, two alternatives are presented. On the one hand, the stack can be built now for the total future requirement. Since closed-in space is at a premium in any institution, unused stack space will be looked upon with avidity by nonlibrary parts of the administration. It is no solution to defeat this avarice by making the stack heights so low that the rooms cannot be used well for anything but stacks, for this defeats the very purpose of the librarian in being able later to abandon stacks for other library uses should the proposals of Rider or others come to fruition. An effort will then usually be made to find some temporary library use for the unoccupied stack or some nonlibrary use which can clearly be abandoned as the holdings increase. Any nonlibrary use must be studied carefully because all experience is that temporary uses have a great way of becoming permanent uses-squatters are influential even in universities-and when people compete with books, people usually (and probably rightly) win. The best solution is, of course, to house some activity for which there is a definite building plan to be consummated in from five to ten years; the next best is to leave the stack space empty and be strong- willed in the ensuing administrative discussions.

The second solution is to build only part of the capacity now and to plan the building so that additions can be made as the collections grow. Here, of course, everything must grow in harmony-not merely the storage space-although it will be easier to save presently unoccupied space for catalogs and catalogers than it will be to save unoccupied stack space. But if this solution is adopted, the minimum requirement should be that the architect provide a fully developed scheme for the ultimate building as well as for the part which is to be currently built. Vague dotted lines indicating that various elements might be expanded this way or that, simply will not do. The expanded building must be known to be workable; it is this expanded building and not what is presently to be created which must be established in the minds of administration and of buildings and grounds committees as the actual building. Otherwise, when the expansion is needed, it may be found that it is architecturally not so possible as the dotted lines had suggested, or will cost too much, or is physically impossible because other buildings, built in the interim, have defeated the original purpose.

When such considerations are held in mind the specter of probable growth does not seem formidable to the committee.

\section{Specter of Change}

The specter of change expresses itself most palpably in the potentials of various technological developments such as microfilm, microprint, microcard, recordings on wires and disks, truly educationtal motion pictures, up to Dr. Bush's Memex. These challenge the imagination and no doubt some of us will live to see some of them realized. It would be well to be more positive than that and to reserve laboratory 
space in libraries so that librarians can make more concrete contributions toward this realization. These developments, as they now stand, have certainly not impressed any member of the committee as adequate reason for postponing construction, say for five years, with the expectation that rapid development would either make the pathway clearer or turn it in a different direction. About the most anyone has been prepared to do, and not all have done that, is to provide some free space which might later be used for such purposes and to design some spaces for use of the techniques in their present form, whether this be for listening to recorded sound or for the use of microfilm readers.

But this is only the most superficial aspect of change; the great one lies in the fluidity of modern education and the uncertainty as to what sort of things may need to be done in a library a decade from now. With uncertainties as great as they must be, the only solution lies in flexibility. Much has been spoken about this subject.

\section{Most Flexible Building}

The most flexible of all buildings is a great assembly plant with large areas free from columns and a great canopy roof overhead. Perhaps the most flexible library building in the United States is the old Army Medical Library in Washington. Both at the State University of Iowa and at Massachusetts Institute of Technology there is an effort to capture a great deal of this flexibility by designing floors of sufficient height (regardless of conventional stack height) so that they can serve for various purposes other than stacks or reading rooms and by designing bays on some sort of universal module so that walls can be placed freely and changed from time to time. The Iowa plan is most complete in this respect.

It has to be recognized that complete flexibility cannot be attained in a modern library building. If air conditioning is needed, and it usually is, ducts will offer limitations to change; so will stairs and other elements of vertical communication. Structure imposes some barriers unless one is to go to unduly costly floor systems. Finally as a library serves more specialized needs, flexibility may serve it less well. A satisfactory auditorium cannot be made either from a visual or an auditory point of view simply by appropriating ten bays of space. Only the most amorphous activities can proceed with equal efficiency in universal space. In seeking universal flexibility we run the risk of creating universal mediocrity. Different libraries will decide differently how far they can go. Great rooms for specialized purposes which are now definable will probably be created outside of the flexible zone and may actually define the character of the building for the casual and nonprofessional passer-by. But it is certainly unnecessary, now, to limit future change by ceilings too low, floors too weak, foundation-to-roof stacks which are too immutable; a library plan of today which does not provide space which can be used interchangeably for storage, work space, seminar, classroom, reading room, and office is not in keeping with the times. Even though all of the libraries will not provide this much flexibility, none will hope to impose on the future use of the building the limitations forced by the monumental interior stair, the monumental library reading room, and the other solid and forbidding appurtenances of The Library Beautiful.

Such are the specters and such are the ways they have been laid by the committee.

The other set of factors are greater in implication and more important, no doubt, in the long run. But, being more general, they are also more difficult to define. The solutions which accord with them will be 
different in different libraries in the measure in which the specific institution has one or another present trend of thought. If the building can be kept flexible within, it is probable that wrong guesses now will not be entirely crippling later. These guesses will be made by a group in the institution of whom the librarian is only one, and in which in these days he all too often has too little influence.

Since the problems we are now discussing are so general they have been the subject of extensive discussion in papers by librarians and others; a paper of this length could scarcely add anything to the present state of thought and it will be adequate to enumerate them as questions which must be answered one way or another before a proper building plan can be made.

Some of them run like this:

I. Should teaching be done in the library? Is the library, in fact, the laboratory of the humanities? Does this imply that faculty offices, seminars, and classrooms should be provided within the library walls?

2. Will serious general education ever be carried on, as it is to some degree now, in the languages, with the major assistance of recorded sound? If so, should the library be the center for this activity ?

3. Should the branch or departmental library system be abandoned because of the probability that it will break down? Liberal arts faculties generally prefer a centralized system, scientific faculties a departmental one. Who is right or are both right? This is one of the oldest questions in library management.

4. With the general trend well established to provide specialized work areas adjacent to stacks storing the pertinent material, should the periodical room be abandoned and the periodicals spread among the specialized collections?

5. Is the general objection to the browsing room one of semantics or something deeper?

6 . Is the reserve book collection the bad teaching tool many librarians think? If so, should reserve book rooms be eliminated?

7. Is the library the inhuman place archi- tects seem to think? This view is supported by many librarians returning from the services. Are we, in fact, too enamored of our tools, and is it true that most of our customers ought not to meet them at the first entrance to the library?

\section{Need a More "Human" Library}

This last question can perhaps stand a little further development. The "human" view says that the library should immediately make the visitor feel that he is at home and happy in a world of booksexpressed by having books, many books, corporeally present and readily accessible. This view holds that the man who needs to do more research will do so anyhow and that the tools can therefore be relegated to a more remote position as they serve only the advanced user of the library.

Many librarians feel, on the other hand, that one of the greatest failures of librarianship has been that it has not succeeded in teaching generations of university students how to use any library as opposed to the geographically familiar one; such a group holds that the tools of bibliography, reference, and catalog, properly used, are a boon to the lazy man and quite as important, though in a different way, to the dilettante as to the scholar. They would, therefore, place these tools in the most prominent and accessible position and, especially, they would not permit the bibliographical materials to be secluded in the catalogers' room.

As between these views, the writer favors that of the librarians. A great school of engineering does not hide its machines in order to make science or engineering more palatable. It makes a virtue of the slide rule. A similar virtue can and should be made of library necessities, for they are part of the equipment of the educated man. They can be made prettier and more efficient; their attendants can be made more competent, more amiable, even more photo- 
genic; much more help can and must be elicited from the faculty in setting problems which cannot be solved without independent use of the library. All of this can be accomplished with a real gain in humanity rather than in the superficial one proposed by an array of fine bindings with or without intervening glass. One could paraphrase the classic remark about the Sterling Library and apply it to books as well.

\section{Generalizations}

In closing, certain generalizations as to physical disposition may be helpful. It seems to be well agreed that all stacks in new buildings should be provided with airconditioning and fumigating facilities. Most members of the committee would extend the air conditioning to the entire building. Lighting remains a confused issue, as it must when the requirements of light for the individual are so much a function of his years and the quality of his eye muscles and when we have to serve so many age groups. It can be expected that.some norms may be required for large spaces but that individual spaces should have light subject to modulation to the needs of the individual rather than to the specifications of makers of electric lighting equipment which increase the lumens year by year on remarkably scanty physiological evidence.

Everyone is anxious to get rid of the great reading rooms. Everyone wants to provide more types of work space in the library, from comfortable lounges to work cubicles, to provide more privacy for more persons, to permit more different habits of work, including the use of the typewriter and the privilege of smoking. There are all sorts of opinions as to whether smoking benefits or harms a library, is dangerous or dirty, and these are almost entirely unsupported opinions. Smokers are more liberal in their opinions about this than nonsmokers, and there are many nonsmokers on library staffs. We do not know enough about tolerable noise levels but it is suspected that the "hush hush" atmosphere of the sanctuary library is a bad thing and that libraries are kept more quiet than they need to be. In any event it is known that more work spaces should be provided where teams of people can converse as they work. Everyone on the committee seems to concur that practically everything should be on the first floormore than most builders will be able to get on the first floor. Where choice must be made the following should remain on the first floor: (I) all public services of bibliography, reference, catalog, delivery desk, stack access; (2) library service of processing from order department to stack; and (3) major reading rooms. Special reading rooms, music rooms, and the like can be allowed to go higher, special studies and work spaces still higher. If all the stipulations for the first floor can still not be met, reading rooms would be given up before the other services.

Questions of theft and mutilation remain unsolved. Some librarians insist on the turnstile as undesirable but essential. Others think it unnecessary and undesirable and will not have it. A recent survey of this question made by M.I.T.'s architect seems to be quite indecisive as to what losses through theft have amounted to anyway. Generally it seems less important than it used to that a library staff employee be able to see every seat in every reading room. Clever mutilators do not need this kind of privacy to achieve their ends.

The plans of the buildings submitted to the committee offer much encouragement. The buildings will surely differ from those of the past and show more differentiation among themselves. Surely they will serve better than the grandiose monuments which have preceded them. 